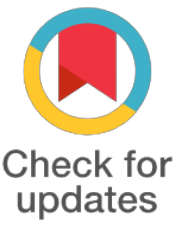

*For correspondence:

shahrulbariyah@usm.my

Competing interests: The authors declare that no competing interests exist.

Received: 2017-06-22 Accepted: 2017-08-12 Published: 2017-09-05

Copyright The Author(s) 2017. This article is published with open access by BioMedPress (BMP).

This article is distributed under the terms of the Creative Commons Attribution License (CC-BY 4.0) which permits any use, distribution, and reproduction in any medium, provided the original author(s) and the source are credited.

\section{Synthesis and Characterization of PLGA-PEG Thymoquinone Nanoparticle and its Cytotoxicity Effects in Tamoxifen-resistant Breast Cancer Cells}

\author{
Rozaina Ahmad, Noor Haida Mohd Kaus, Shahrul Hamid
}

Advance Medical and Dental Institute Universiti Sains Malaysia

Bertam, Pulau Pinang 13200, Malaysia

\section{Abstract}

Background: Drug resistance has been a continuous challenge in cancer treatment. The use of nanotechnology in the development of new cancer drugs has potential. One of the extensively studied compound is thymoquinone (TQ) and this work aims to compare two types of TQnanoformulation and its cytotoxicity towards resistant cancer cells.

Methods: TQ-nanoparticles were prepared and optimized by using 2 different formulation with different drug to PLGA-PEG ratio (1:20 and 1:7) and different PLGA-PEG to pluronic F68 ratio (10:1 and 2:1). The morphology and size were determined using TEM and DLS. Characterization of particles were done using UV-VIS, ATR-IR, entrapment efficiency and drug release. The effects of drug, polymer and surfactants were compared between the two formulations. Cytotoxicity assay was performed using MTS assay.

Results: TEM finding showed $96 \%$ of particles produced with 1:7 drug to PLGA-PEG were less than $90 \mathrm{~nm}$ in size and spherical in shape. This was confirmed with DLS which showed smaller particle size than those formed with 1:20 drug to PLGA-PEG ration. Further analysis showed zeta potential was negatively charge which could facilitate cellular uptake as reported previously. In addition, PDI value was less than 0.1 in both formulations indicating monodispersed and less broad in size distribution. The absorption peak of PLGA-PEG-TQ-Nps were at $255 \mathrm{~nm}$. The 1:7 drug to polymer formulation was selected for further analysis where the entrapment efficiency was $79.9 \%$ and in vitro drug release showed a maximum release of TQ at $64 \%$ respectively. Cytotoxicity result showed IC 50 of TQ-nanoparticle at $20.05 \mu \mathrm{M}$ and free TO was $8.25 \mu \mathrm{M}$.

Conclusion: This study showed that nanoparticle synthesized with 1:7 drug to PLGA-PEG ratio and 2:1 PLGA-PEG to pluronic F68 were less than $100 \mathrm{~nm}$ and had spherical shape as confirmed with DLS. This could facilitate its transportation and absorption to reach its target. There was conserved TO stability as exhibited by slow release of this volatile oil. Cytotoxicity effect was noted when resistant breast cancer cells were treated with these particles.

\section{Keywords}

Breast cancer, Drug resistance, PLGA-PEG, Thymoquinone nanoparticle

\section{Funding}

RUI grant (1001/CIPPT/812138) 